\title{
AVALIAÇÃO DA CAPACIDADE POTENCIAL DE ARMAZENAMENTO DE ÁGUA NA BACIA HIDROGRÁFICA DO RIO PEQUENO, SÃO JOSÉ DOS PINHAIS, PR
}

\author{
Richardson Guenther Schechi ${ }^{1}$, Rita de Cássia Bianchi ${ }^{2}$, Rafael Zoboli Guimarães ${ }^{3}$, \\ Nivaldo Eduardo Rizzi ${ }^{4}$ \\ ${ }^{1}$ Eng. Florestal, M.Sc., Doutorando em Eng. Florestal, UFPR, Curitiba, PR, Brasil - engrichardson@ gmail.com \\ ${ }^{2}$ Eng $^{\mathrm{a}}$. Florestal, M.Sc., UFPR, Curitiba, PR, Brasil - risobianchi@ yahoo.com.br \\ ${ }^{3}$ Eng. Ambiental, M.Sc. Engenharia Florestal, UFPR, Curitiba, PR, Brasil - rzguimaraes@gmail.com \\ ${ }^{4}$ Eng. Florestal, Dr., Depto. de Engenharia e Tecnologia Florestal, UFPR, Curitiba, PR, Brasil - niva@ufpr.br \\ Recebido para publicação: 11/04/2012 - Aceito para publicação: 24/04/2013
}

\begin{abstract}
Resumo
O presente trabalho demonstra a capacidade potencial de armazenamento de água da bacia hidrográfica do rio Pequeno, São José dos Pinhais, PR, que é uma região de crescente expansão urbana e industrial da Região Metropolitana de Curitiba. Com a análise da capacidade potencial de armazenamento de água da bacia hidrográfica, podem ser identificadas áreas com maior ou menor capacidade de recarga de aquíferos, auxiliando, dessa maneira, na implementação de políticas de desenvolvimento socioeconômicas. Para tanto, foi aplicada a metodologia de avaliação da capacidade potencial de armazenamento de água proposta por Chiaranda (2002), que consiste na análise e cruzamento, em ambiente de Sistemas de Informações Geográficas (SIG), de informações temáticas como geologia, geomorfologia, solo, cobertura vegetal original e usos dos solos nos anos de 1986, 1996 e 2007. No ano de 1986, a bacia apresentou 79,39; 49,38 e 1,68\%, e em 2007 a bacia apresentou 74,$10 ; 47,73$ e $8,62 \%$ de sua área enquadrada nas classes de alta, média e baixa capacidade de armazenamento, respectivamente. Verificou-se que os usos da terra modificaram as características da capacidade potencial de armazenamento da bacia do rio Pequeno.

Palavras-chave: Recursos hídricos; capacidade de armazenamento; hidrologia florestal.
\end{abstract}

\begin{abstract}
Evaluation of potential water storage capacity in the Rio Pequeno watershed, São José dos Pinhais, $P R$. This work demonstrates the potential water storage capacity of Rio Pequeno watershed, located in the municipality of São José dos Pinhais, in Paraná State, Brazil. The city is part of Curitiba Metropolitan Area and presents high urban and industrial development. The analysis of the Rio Pequeno watershed potential water storage capacity can identify areas of aquifers with higher or lower capacity to recharge, due to implementation of socioeconomic development policies. In order to that, it was applied the methodology of assessment of potential water storage capacity proposed by Chiaranda (2002). It consists in a Geographical Information System (GIS) analysis combined to different sources of information, such as geology, soil type, original plant cover and land uses. The methodology was applied to the years of 1986, 1996, and 2007. In 1986 the basin presented 79.39, 49.38 , and $1.68 \%$, in 2007 the basin presented 74.10, 47.73, and 8.62\% of its framed area in classes of high, medium and low storage capacity, respectively. According to that, it was observed that land uses have changed the characteristics of potential water storage capacity of Rio Pequeno watershed. Keywords: Water resources; storage capacity; forest hydrology.
\end{abstract}

\section{INTRODUÇÃO}

Os recursos hídricos estão sendo comprometidos pela degradação urbana, industrial, agrícola e por desequilíbrios ambientais resultantes do desmatamento e uso indevido do solo. A cada dia cresce a disputa entre os setores da agricultura, indústria e abastecimento humano, que tradicionalmente competem pelo uso da água, gerando sérios conflitos entre os usuários. Portanto, torna-se imprescindível a tomada de decisões de forma cuidadosa, bem como a verificação do impacto do crescimento na 
utilização de tais recursos. Entre os problemas ambientais que acompanham o crescimento populacional está a redução dos espaços permeáveis do solo. Essa impermeabilização causa comprometimento das bacias hidrográficas, sob o ponto de vista da recarga dos aquíferos, além disso, merece uma atenção especial, visto que a compatibilização da preservação ambiental com as atividades humanas é revestida de grande complexidade (ALMEIDA; BRITTO, 2002; MATTAR NETO et al., 2009).

A bacia do rio Pequeno constitui um importante manancial para abastecimento público, industrial e agrícola da Região Metropolitana de Curitiba (RMC). Cerca de 57\% da área da bacia consistem em Área de Proteção Ambiental (SANTOS, 2006). Essa bacia é parte integrante do plano de recursos hídricos da bacia do Alto Iguaçu. Como a disponibilidade hídrica da RMC é restrita, o planejamento do uso de seus mananciais deve ser cuidadosamente avaliado (ANDREOLI et al., 2000).

Um dos principais focos de expansão urbana da RMC encontra-se na porção sudoeste da subbacia do rio Pequeno (SANTOS; BERTOTTI, 2009). O crescimento da área urbana do município de São José dos Pinhais é inevitável, em virtude do crescimento populacional e das migrações para a região. Portanto, a crescente necessidade da sociedade por infraestrutura, bens e serviços torna o desenvolvimento das atividades socioeconômicas primordiais e incontestáveis. Todas as atividades relacionadas com o crescimento de um município modificam as condicionantes hidrológicas da região, afetando diretamente a capacidade potencial de armazenamento, ou seja, o máximo possível de armazenamento de água de uma bacia hidrográfica (AMARAL, 2002; SCHECHI, 2012). Diante desse contexto, torna-se cada vez mais urgente o planejamento físico territorial não só com enfoque socioeconômico da região, mas também ambiental, levando-se em consideração não apenas as potencialidades, mas também a fragilidade das áreas com intervenções antrópicas (SOARES, 2008).

A utilização de indicadores ambientais torna-se importante para a tomada de decisão à medida que as atitudes do ser humano refletem no meio ambiente, formando cadeias de ação-resposta e permitindo uma verificação dos impactos causados (MATTAR NETO et al., 2009). De acordo com Braun (2008), indicadores são considerados pré-requisito para a implementação de uma política de sustentabilidade ambiental. O uso de indicadores é justificado pela impossibilidade de realizar medições diretas em muitos programas de monitoramento, devido a problemas metodológicos ou a questões práticas, como custos e tempo, e pela falta de viabilidade de muitos modelos de simulação, que foram desenvolvidos como uma alternativa para as medições diretas.

A capacidade potencial de armazenamento de água é influenciada por variáveis de ordem geológica, geomorfológica, edáfica, de relevo e de uso do solo. O objetivo deste trabalho consiste na aplicação de um modelo de avaliação da capacidade potencial de armazenamento de água, cujo resultado consiste de um indicador cartográfico que permite a diferenciação de áreas com maior ou menor capacidade de armazenamento na sub-bacia do rio Pequeno. Esse indicador visa permitir um manejo mais adequado dos recursos hídricos da região, auxiliando na criação de políticas de proteção dessas áreas.

\section{MATERIAL E MÉTODOS}

A sub-bacia hidrográfica do rio Pequeno (Figura 1) pertence à bacia hidrográfica do Alto Iguaçu, apresenta área total de drenagem de $130 \mathrm{~km}^{2}$ (13000 ha) e limites localizados integralmente no município de São José dos Pinhais, no quadrilátero formado pelas coordenadas $25^{\circ} 29^{\prime}$ e $25^{\circ} 37^{\prime}$ de latitude sul e os meridianos $48^{\circ} 48^{`}$ e $49^{\circ} 11^{`}$ de longitude oeste (SANTOS; BERTOTTI, 2009).

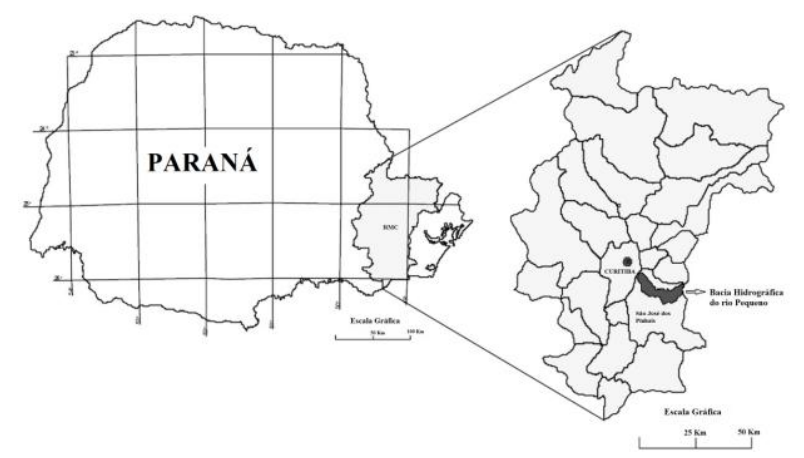

Figura 1. Localização da bacia hidrográfica do rio Pequeno.

Figure 1. Location of rio Pequeno watershed.

Fonte: Santos e Kobiyama, 2004. 
A metodologia de pesquisa utilizada para determinar a capacidade potencial de armazenamento de água foi desenvolvida por Chiaranda (2002) e é estruturada de maneira lógica, a fim de facilitar as etapas de trabalho, conforme "Os Quatro Níveis da Pesquisa Geográfica" proposto por Libault (1971). Através deste, foi elaborado um Modelo de Análise em Ambiente de Sistema Geográfico, com a finalidade de elaboração das cartas de síntese, com o auxílio do aplicativo ArcGis 9.3 da ESRI. A metodologia divide o desenvolvimento da pesquisa em quatro partes:

1) Nível compilatório: Constitui a aquisição de mapas temáticos, observações em campo sobre a estrutura da paisagem e a seleção dos dados que têm valor para a pesquisa. A delimitação da bacia hidrográfica foi feita pelo setor de geoprocessamento da AGUASPARANA em 2010, utilizando-se as cartas do IBGE, nas escalas 1:50.000 e 1:100.000, digitalizadas e georreferenciadas no datum SAD-69. Os mapas temáticos que representam as unidades tipológicas de geologia, geomorfologia, declividade, uso do solo, fitogeografia e hidrografia (escala 1:2.000.000) foram disponibilizados através do site do Instituto de Terras, Cartografia e Geociências (ITCG).

Os mapas de uso do solo foram elaborados através de classificação de imagens de satélite obtidas através do Instituto Nacional de Pesquisas Espaciais (INPE). As imagens utilizadas foram imagens multiespectral TM-Landsat 5, órbita ponto 220/78 dos anos de 1986, 1996 e 2007, que recobrem a área de estudo. Para o processamento das imagens de satélite, foi utilizado o software ENVI 4.5 - Environment for Visualizing Images. As tipologias adotadas foram baseadas nas recomendações do Instituto Brasileiro de Geografia e Estatística (IBGE) para a classificação da vegetação brasileira, sendo elas Floresta, Capoeira, Várzea, Reflorestamento, Campos, Urbano e Agricultura.

2) Nível correlativo: Constitui a interpretação e correlação dos dados, conforme demostrado na tabela 1. Os dados apresentados na tabela 1 representam a expressão hidrológica das unidades homogêneas, divididas em classes de importância e valoradas.

A expressão hidrológica de cada unidade tipológica se refere à influência na capacidade potencial de recarga do aquífero, denominadas mapas temáticos base.

Os mapas temáticos derivados utilizados neste trabalho são:

- Mapa de Geologia: Mapa de Permeabilidade.

- Mapa de Geomorfologia: Mapa de Fluxo Preferencial em Profundidade e Mapa de Declividade.

- Mapa de Solos: Mapa de Potencial de Infiltração e Potencial para Armazenamento.

- Mapa de Usos do Solo: Mapa de Grau de Proteção.

3) Nível semântico: Constitui a primeira integração entre os mapas obtidos no nível correlativo através da ponderação, resultando em dois mapas intermediários I e um mapa intermediário II, detalhados a seguir. Os mapas intermediários I correspondem aos mapas do potencial hidrológico do relevo e do solo. $\mathrm{O}$ potencial hidrológico do relevo é o produto da integração das expressões hidrológicas Fluxo Preferencial em Profundidade e Declividade e representa a expressão hidrológica que caracteriza no espaço a componente física geomorfologia. Já para o mapa de potencial hidrológico do solo, foram considerados o Potencial de Infiltração e o Potencial da Profundidade para Armazenamento, que expressam no espaço a componente física solo. Através dessas integrações, buscou-se a essência da expressão hidrológica de cada uma dessas componentes do meio físico (SCHECHI, 2012).

No que diz respeito ao mapa do potencial hidrológico do relevo, foram atribuídos pesos aos temas derivados da componente geomorfologia, sendo eles o Fluxo Preferencial em Profundidade (peso 0,333) e a Declividade (peso 0,667). Da mesma maneira, para o mapa de potencial hidrológico do solo foram atribuídos pesos aos temas derivados da componente solos, sendo eles Potencial de Infiltração (peso 0,333) e Fluxo Preferencial em Profundidade (peso 0,667). O resultado da ponderação da integração foi distribuído nas seguintes classes de importância: muito alta $(0,8-1,0)$, alta $(0,6-0,799)$, média $(0,4-$ $5,99)$, baixa $(0,2-3,99)$ e muito baixa $(0,0-1,99)$.

O mapa intermediário II corresponde ao mapa de Capacidade Potencial de Armazenamento do Meio Poroso, que é a expressão hidrológica que representa as quantidades potenciais de água que o volume poroso existente no meio (rochas e solo) pode armazenar (CHIARANDA, 2002). Esse mapa foi confeccionado pela atribuição de peso e compilação do tema derivado da componente geologia 
(permeabilidade das rochas - peso 0,297) e dos mapas intermediários I (mapa do potencial hidrológico do relevo - peso 0,163, e mapa do potencial hidrológico do solo - peso 0,540). Os intervalos de classes de fatiamento para potencial de armazenamento do meio poroso foram atribuídos da mesma maneira ao descrito acima para os mapas intermediários I. O resultado da ponderação da integração foi distribuído nas seguintes classes de importância: muito alta $(0,8-1,0)$, alta $(0,6-0,799)$, média $(0,4-5,99)$, baixa $(0,2-$ $3,99)$ e muito baixa $(0,0-1,99)$.

Tabela 1. Quantificação da expressão hidrológica das componentes.

Table 1. Measurement of hydrologic expression of components.

\begin{tabular}{|c|c|c|c|c|c|}
\hline Expressão hidrológica & Classe & Pesos & Área $\left(\mathbf{k m}^{2}\right)$ & $\%$ & Unidades homogêneas base \\
\hline \multirow[t]{3}{*}{ Permeabilidade } & Alta & 0,8 & 22,34 & 17,13 & Aluviões e Terraços \\
\hline & Média & 0,6 & 27,44 & 21,03 & Formação Guabirotuba \\
\hline & Baixa & 0,4 & 80,67 & 61,84 & $\begin{array}{l}\text { Complexo Gnáissico-Migmatítico } \\
\text { Complexo Granítico-Gnáissico }\end{array}$ \\
\hline \multirow{3}{*}{$\begin{array}{l}\text { Fluxo preferencial em } \\
\text { profundidade }\end{array}$} & Alta & 0,8 & 57,64 & 44,20 & Planalto de Curitiba \\
\hline & Média & 0,6 & 6,99 & 5,36 & Blocos Soerguidos da Serra do Mar \\
\hline & Baixa & 0,4 & 65,82 & 50,48 & $\begin{array}{c}\text { Planalto do Alto Iguaçu } \\
\text { Planícies Fluviais }\end{array}$ \\
\hline \multirow[t]{5}{*}{ Declividade } & Muito Alta & 0,2 & 0,09 & 0,07 & Escarpado \\
\hline & Alta & 0,4 & 8,92 & 6,84 & Montanhoso \\
\hline & Média & 0,6 & 36,89 & 28,28 & Ondulado a Forte Ondulado \\
\hline & Baixa & 0,8 & 22,41 & 17,18 & Suave Ondulado \\
\hline & Muito Baixa & 1 & 62,14 & 47,64 & Plano \\
\hline \multirow{3}{*}{$\begin{array}{l}\text { Potencial de infiltração do } \\
\text { solo }\end{array}$} & Alta & 0,8 & 29,32 & 22,47 & Latossolo \\
\hline & Média & 0,6 & 68,53 & 52,52 & $\begin{array}{l}\text { Argissolo } \\
\text { Cambissolo }\end{array}$ \\
\hline & Baixa & 0,4 & 32,63 & 25 & $\begin{array}{c}\text { Afloramento de Rocha/Neossolo Litólico } \\
\text { Gleissolo/Organossolo }\end{array}$ \\
\hline \multirow[t]{4}{*}{$\begin{array}{l}\text { Potencial da profundidade } \\
\text { para armazenamento }\end{array}$} & Alta & 1 & 52,23 & 40,04 & $\begin{array}{l}\text { Latossolo } \\
\text { Cambissolo }\end{array}$ \\
\hline & Média & 0,75 & 45,62 & 34,97 & Argissolo \\
\hline & Baixa & 0,5 & 30,64 & 23,49 & Gleissolo / Organossolo \\
\hline & Muito Baixa & 0,25 & 1,99 & 1,52 & Afloramento de Rocha/Neossolo Litólico \\
\hline \multirow{5}{*}{$\begin{array}{l}\text { Grau de proteção dos usos } \\
\text { do solo }\end{array}$} & Muito Alto & 1 & & & Floresta \\
\hline & Alto & 0,8 & & & $\begin{array}{l}\text { Reflorestamento } \\
\text { Capoeira }\end{array}$ \\
\hline & Médio & 0,6 & & & Campo \\
\hline & Baixo & 0,4 & & & $\begin{array}{l}\text { Várzea } \\
\text { Aoricultura }\end{array}$ \\
\hline & Muito Baixo & 0,2 & & & Urbano \\
\hline
\end{tabular}

Fonte: SCHECHI (2012).

4) Nível normativo: Constitui a fase de elaboração do modelo, representado através de mapas finais ou gráficos que traduzem de forma mais simples e visual os resultados da pesquisa. Os mapas finais são os mapas de capacidade potencial de armazenamento dos anos de 1986, 1996 e 2007. A elaboração dos mapas finais foi efetuada pela ponderação e integração do potencial de armazenamento do meio poroso da bacia (peso 0,333 ) com o grau de proteção (peso 0,667 ) proporcionado pelos usos da terra nos anos de 1986, 1996 e 2007. O grau de proteção refere-se aos estágios sucessivos de uma progressão de efeitos de defesa ou proteção que os diferentes tipos de cobertura proporcionam ao solo contra a ação direta dos ventos, da radiação solar e dos eventos de precipitação. Para o grau de proteção da cobertura vegetal, foram determinadas sete classes, conforme dados descritos na tabela 1. Para um melhor entendimento da metodologia, foi elaborado o fluxograma representado na figura 2. 


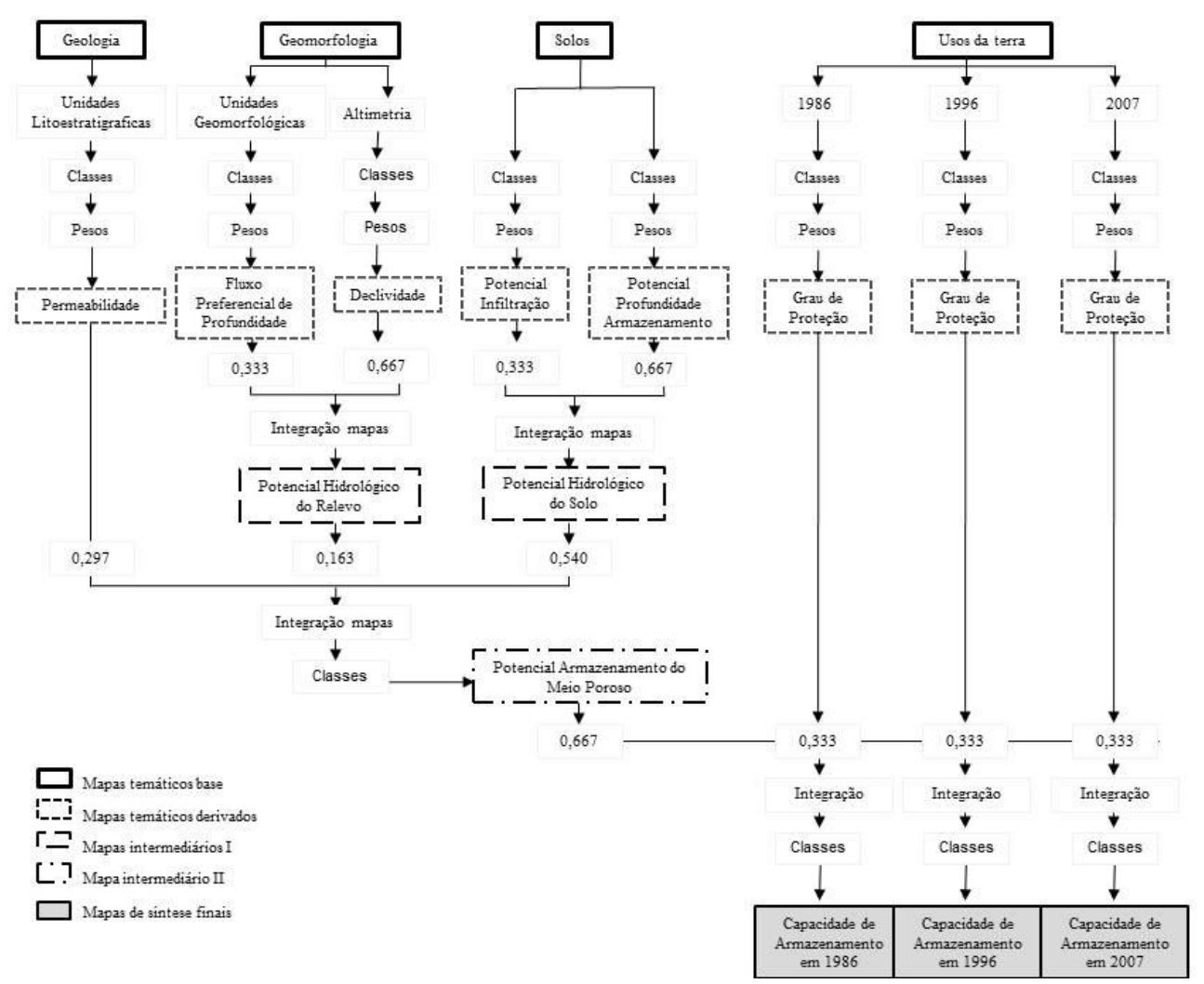

Figura 2. Fluxograma da metodologia de trabalho.

Figure 2. Flowchart of the work method.

\section{RESULTADOS E DISCUSSÃO}

O potencial de armazenamento do meio poroso (mapa intermediário II) (figura $3 \mathrm{~A}$ ), elaborado pela integração dos temas permeabilidade das rochas, potencial hidrológico do relevo e potencial hidrológico do solo (mapa intermediário I), apresentou classe de potencial muito alta. Isso representa um percentual pequeno da bacia, apenas 1,29\%, predominando nessas áreas os fluxos lentos de infiltração, percolação e escoamento-base, devido às características físicas das rochas, dos solos e do relevo. Nas áreas classificadas como muito alta para potencial de armazenamento para meio poroso predominam as classes de potencial hidrológico do solo muito alta e potencial hidrológico do relevo variando de muito alta a alta, situação esta de ocorrência nas regiões geomorfológicas do planalto e planícies fluviais do alto rio Iguaçu.

A classe alta para potencial representa a maior porção da bacia $(63,95 \%)$ e corresponde à integração das classes de potencial hidrológico do relevo e do solo, que variam predominantemente entre as classes média a alta, de ocorrência nas regiões geomorfológicas do Planalto de Curitiba e na Planície Fluvial. As classes de permeabilidade das rochas variam de baixa a alta, correspondendo aos Aluviões Atuais, à Formação Guabirotuba e ao Complexo Gnaíssico-migmatítico. As classes de baixa permeabilidade correspondem ao Complexo Gnaíssico-migmatítico, contudo apresentam solos profundos, o que as fez fazerem parte desta classe de alto potencial de armazenamento do meio poroso. Essas características apresentam fluxos lentos de infiltração, percolação e escoamento-base, devido às características físicas das rochas, dos solos e do relevo, com intensidade relativamente menor que aquela que ocorre na classe de potencial muito alto.

A classe de potencial médio corresponde a 33,35\% da área da bacia e é resultante da integração das classes de alta, média e baixa permeabilidade, com as classes de médio e baixo potencial hidrológico 
do solo e classes de muito alto, alto e médio potencial hidrológico do relevo. São áreas onde ocorre a presença de declividades mais acentuadas e solos mais rasos, conferindo a essa classe de potencial de armazenamento do meio poroso condições em que as componentes de fluxo são lentas enquanto não ocorre a saturação em períodos chuvosos e de fluxos mais rápidos após a saturação dos poros. A classe de baixo potencial corresponde a $1,41 \%$ da área da bacia e é resultado da integração das classes de baixa permeabilidade com as classes de médio e baixo potencial hidrológico do relevo e do solo. Essas áreas estão localizadas em sua maior sobre os Blocos Soerguidos da Serra do Mar, com solos rasos e declividades acentuadas, o que confere a essas regiões altos fluxos de água.
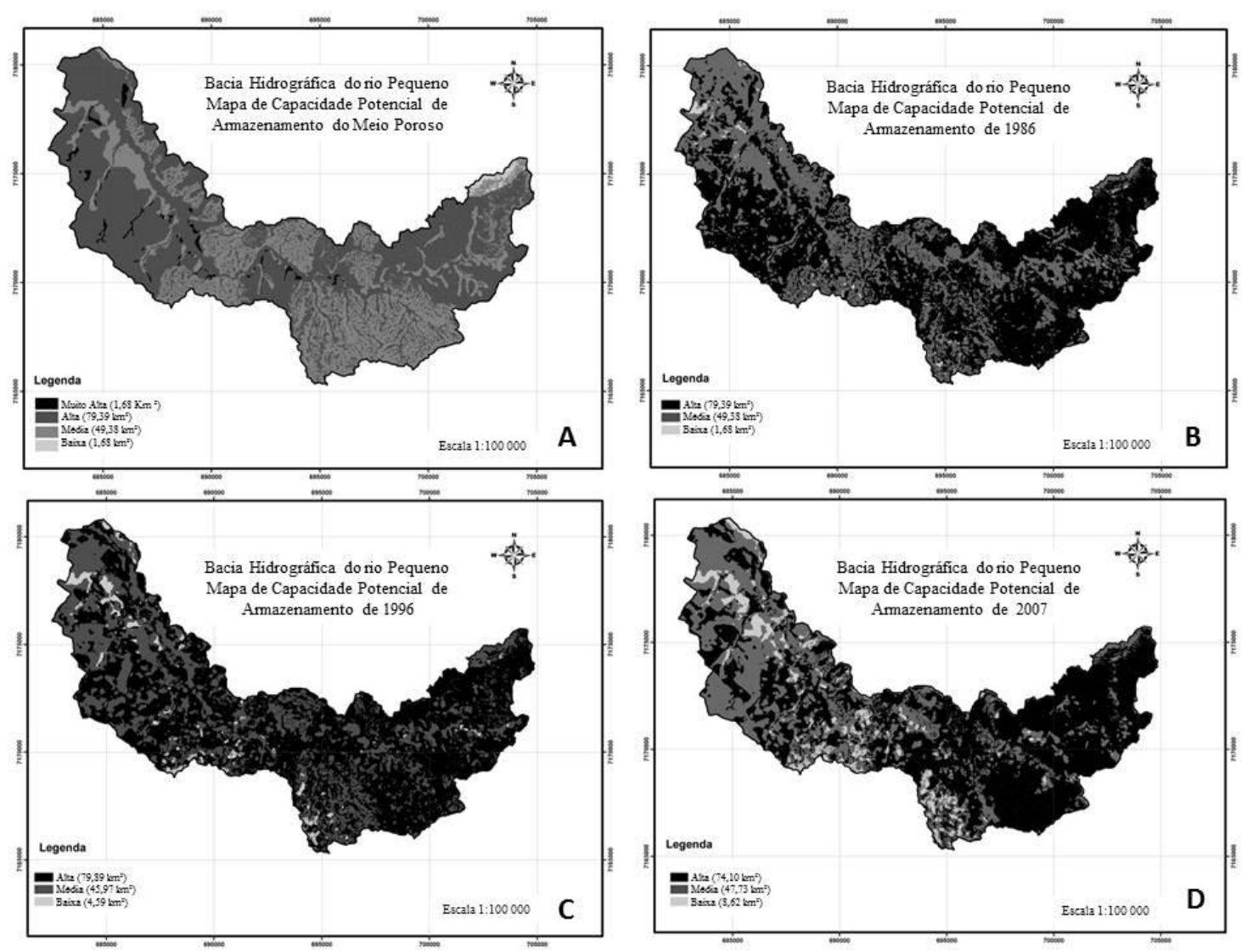

Figura 3. A - Mapa de Capacidade Potencial de Armazenamento do Meio Poroso. B - Mapa da capacidade potencial de armazenamento no ano de 1996. C - Mapa da capacidade potencial de armazenamento no ano de 1996. D - Mapa da capacidade potencial de armazenamento no ano de 2007.

Figure 3. A - Map of potential storage capacity of the porous environment. B - Maps of potential storage capacity in 1986. C - Maps of potential storage capacity in 1996. D - Maps of potential storage capacity in 2007.

Considerando que os valores de classes de capacidade potencial de armazenamento de água da bacia podem vir a ser alterados em virtude do crescimento populacional e da expansão territorial (BRAUN, 2008), foi avaliada a alteração da capacidade potencial de armazenamento nos anos de 1986, 1996 e 2007. Para esse fim, inicialmente foi avaliado o grau de proteção dos usos do solo (tabela 1) no período e os resultados obtidos estão demonstrados na figura 4, onde se verifica que a única classe que mantém um padrão de expansão é a classe muito baixa, a qual, em termos de uso do solo, é representada pela classe Urbano. A continuidade observada para essa classe reflete o crescimento urbano do município, que passou de 5,05\% para 25,04\% sobre o grau de proteção no decorrer de 21 anos. Em contrapartida, a 
classe baixa, que, em termos de uso do solo, corresponde às classes de várzea e agricultura, apresentou um padrão contínuo de retração, que pode ser explicado pelo desenvolvimento urbano da Região Metropolitana de Curitiba e consiste de 18,23\% em 21 anos.

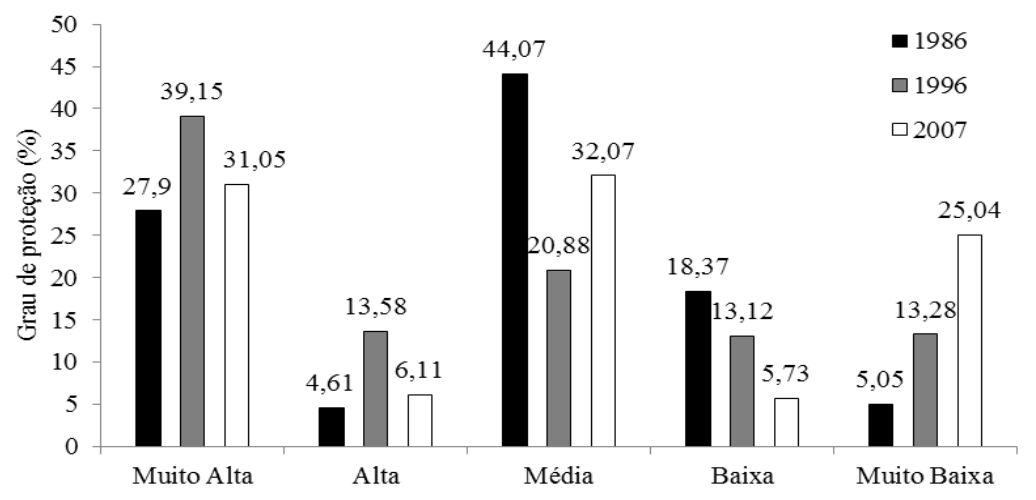

Figura 4. Grau de proteção dos usos da terra nos anos de 1986, 1996 e 2007.

Figure 4. Protection grade of land uses in the years 1986, 1996 and 2007.

A classe de grau de proteção média, que se refere à classe Campos, apresentou uma descontinuidade de retração e expansão. Nos primeiros 10 anos (1986-1996) analisados, ela sofreu uma retração de 23,19\%, e nos 11 anos seguintes (1996-2007) sofreu uma expansão de 11,19\%. Um padrão similar foi obtido para a classe de grau de proteção alta (capoeira e reflorestamento) nos primeiros 10 anos avaliados, com expansão de 8,97\%, e retração de 7,11\% nos 11 anos subsequentes. A classe de grau de proteção muito alta (Floresta) apresentou uma expansão de $11,25 \%$ entre 1986 e 1996 e uma retração de 8,1\% entre 1996 e 2007. Uma das possíveis explicações para essa retração consiste no reflexo dos loteamentos que estão sendo feitos nas áreas de cabeceira da bacia (TAVARES, 2005).

A geração dos mapas-síntese finais, que representam as áreas responsáveis pelo armazenamento de água, foi realizada através da integração do mapa do Potencial de Armazenamento do Meio Poroso (mapa intermediário II) com os mapas temáticos derivados do grau de proteção do uso da terra nas diferentes décadas. Os resultados obtidos dessas integrações estão representados na figura $5 \mathrm{em}$ forma de percentuais e na figura $3-\mathrm{B}, \mathrm{C}$ e D - na forma de mapas contendo a extensão em $\mathrm{km}^{2}$ de cada uma das classes nos anos de 1986, 1996 e 2007, respectivamente.

No ano de 1986, como pode ser observado na figura 3B, a capacidade de armazenamento que corresponde à classe média era dominante na bacia (61\% de sua área), seguida pela classe alta $(35 \%)$. As classes baixa e muito baixa correspondiam a apenas uma pequena porção da área da bacia $(0,8 \%)$. Com o passar do tempo, em 1996, a classe alta passou a ser predominante, com área de 61\%, seguida pela classe média $(35 \%)$. Nesse ano foi observado um aumento da classe de baixa capacidade de armazenamento (3,5\%, Figura 3C). Segundo Lima e Mendonça (2001), em São José dos Pinhais, nos anos 90, o número de ocupações em mananciais cresceu 34,93\% em apenas cinco anos. Na década de 1990 surgiu uma preocupação com as ocupações irregulares, devido à expansão da malha urbana sem planejamento e para áreas sem infraestrutura, configurando um processo de periferização (AMARAL, 2002). Tais preocupações decorrem do fato de que a expansão urbana ocorreu, em sua maioria, sobre os mananciais de abastecimento público.

Passados mais 11 anos, em 2007, (Figura 3D) não foram observadas alterações significativas nas classes alta e média, porém a classe de baixa capacidade de armazenamento apresentou sua área dobrada $(6,6 \%)$ em relação a 1996. Na década de 2000, ocorreu o crescimento do município devido principalmente à instalação do polo industrial da montadora Audi/Volkswagem e de suas fornecedoras de complementos. A instalação de mais esse distrito industrial no município aumentou a preocupação com relação à disponibilidade e qualidade de água na RMC (AMARAL, 2002). De maneira similar, Soares et al. (2011b) demonstraram que a evolução da ocupação na bacia do rio Pequeno aumentou a urbanização, a exploração agrícola e o solo exposto em $12 \%$ da área. Consequentemente, parte da área ocupada com 
vegetação natural em 2000 foi reduzida para 11\% em 2006, tornando-a mais sensível à exposição aos processos erosivos.

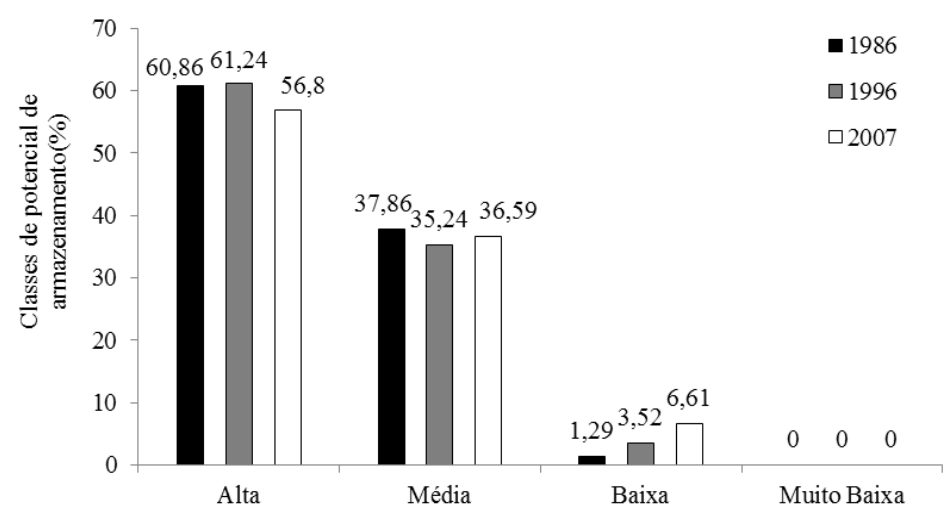

Figura 5. Classes de capacidade potencial de armazenamento.

Figure 5. Classes of potential storage capacity.

Grande parte das modificações da estrutura de uso do solo, como as alterações das classes naturais para classes antrópicas, vem a ser geradas em função das políticas de desenvolvimento socioeconômico de expansão da Região Metropolitana de Curitiba. A instalação do Distrito Industrial de São José dos Pinhais e os reflexos socioespaciais não fugiram à regra de outros parques industriais instalados no País. A implantação do complexo automotivo do Paraná (Renault), a partir de meados dos anos 1990, seguiu o mesmo modelo de outros distritos ou plantas industriais e, também, produziu transformações socioespaciais muito semelhantes, como crescimento populacional, novas atividades econômicas e a ocupação até de uma área utilizada como manancial de abastecimento público, a bacia hidrográfica do rio Pequeno (TAVARES, 2005).

No decorrer das três décadas contempladas pelo estudo, contata-se que as reduções ocorridas nas classes de alta capacidade de armazenamento para a média foram principalmente reflexos dos desmatamentos e do crescimento das classes de campo e capoeira. A crescente impermeabilização do solo observada veio a ser a principal responsável pela alteração das classes de média e alta para baixa capacidade de armazenamento, além de modificar as propriedades de proteção e defesa que a cobertura vegetal fornece ao solo. Segundo Chiaranda (2002), o aumento da baixa capacidade potencial de armazenamento é o que mais preocupa, uma vez que aumenta a impermeabilização do terreno e diminui a infiltração, afetando diretamente a estrutura hidrológica da paisagem, uma vez que eleva o escoamento superficial direto e modifica o comportamento do deflúvio. Essa impermeabilização pode ser decorrente da presença de aglomerados urbanos e chácaras de lazer, as quais são consideradas por Santos e Bertotti (2009) características importantes da área da bacia, o que também foi verificado por Soares et al. (2011a). O crescimento das áreas de chácaras de lazer está diretamente relacionado com a retração das áreas de alta capacidade de armazenamento, uma vez que retiram a cobertura florestal para inserir em seu lugar áreas para o lazer, como campos e áreas de pastagem, entre outras. A abordagem sistêmica de análise de geologia, geomorfologia, declividade, uso do solo, fitogeografia e hidrografia permitiu a identificação dos elementos e variáveis mais importantes, bem como das relações que existem entre eles.

Diante dos efeitos negativos dos usos dos recursos naturais sobre a capacidade potencial de armazenamento de água da bacia e diante do quadro de incertezas quanto à satisfação atual e futura da demanda por recursos hídricos, a implementação de políticas de gerenciamento ambiental em bacias hidrográficas é necessária e deve ser realizada através do manejo integrado desses recursos. Para isso, torna-se necessária a obtenção de informações que alicercem o planejamento das intervenções futuras, por meio de avaliação e controle da degradação que poderá vir a ocorrer, justificando-se a confecção de indicadores ambientais como os obtidos neste trabalho. O controle ambiental na forma de uma melhoria das condições de armazenamento de água em uma bacia vem a ser uma ação alternativa econômica e duradoura para a minimização dos efeitos causados pelos usos da terra (GUIMARÃES, 2000). 
Contudo, quando se trata da capacidade de armazenamento de uma bacia hidrográfica, alguns cuidados devem ser tomados, principalmente na interpretação e nos usos dos mapas de capacidade de armazenamento. Esses mapas não podem ser considerados como medida direta da capacidade de recarga, mas sim como uma indicação, pois a capacidade potencial de armazenamento refere-se ao volume de água que pode ser acumulado ou retido temporariamente no meio poroso. Já a capacidade de recarga está relacionada ao balanço existente entre a precipitação incidente e o escoamento superficial, ou seja, a quantidade do armazenamento nas depressões superficiais, no solo e no lençol freático (CHIARANDA, 2002; BRAUM, 2007).

\section{CONCLUSÕES}

- O presente trabalho pautou-se na utilização da metodologia de análise proposta por Chiaranda (2002), baseada nos princípios de funcionamento das bacias hidrográficas e nos conceitos de estrutura hidrológica da paisagem, possibilitando assim avaliar o estágio de modificação hidrológica da paisagem através da capacidade potencial de armazenamento. Com base nos resultados obtidos, constata-se que os usos da terra alteraram significativamente a capacidade potencial de armazenamento da bacia hidrográfica e não houve um padrão de continuidade de expansão ou retração das classes de capacidade potencial de armazenamento. A diferença do percentual de áreas em cada classe de solo entre 1986 e 2007 indica um crescimento de 19,98\% para a classe urbano, $3,15 \%$ para floresta, $1,46 \%$ para agricultura e 1,07\% para a classe capoeira. Em contrapartida, retrações foram obtidas para as classes várzea $(14,10 \%)$, seguida pela classe campo (12\%). O dado mais preocupante consiste no aumento significativo da classe de baixo potencial de armazenamento, de 0,4 para $6,6 \%$, a qual está diretamente relacionada à impermeabilização do solo.

- A avaliação da capacidade potencial de armazenamento de água forneceu informações que podem auxiliar no planejamento da expansão territorial da bacia hidrográfica do rio Pequeno, em decorrência da necessidade de informações que alicercem o planejamento das intervenções futuras por meio da avaliação e controle das alterações que poderão a vir a ocorrer.

\section{REFERÊNCIAS}

ALMEIDA, J.; BRITO, A. G. A utilização de indicadores ambientais como suporte ao planejamento e gestão de recursos hídricos: o caso da região autônoma dos Açores. In: III CONGRESO IBERICO SOBRE GESTIÓN Y PLANIFICACIÓN DEL ÁGUA, Anais... Sevilla, 2002. p. 10.

AMARAL, S. B. Aspectos da relação entre uso do solo e qualidade da água na bacia do rio Pequeno, São José dos Pinhais, PR. Dissertação (Mestrado em Geografia) - Universidade Federal do Paraná, Curitiba, 2002.

ANDREOLI, C. V.; DALARMI, O.; LARA, A. I.; ANDREOLI, F. N. Limites ao desenvolvimento da Região Metropolitana de Curitiba impostos pela escassez de água. In: $9^{\circ}$ SILUBESA - Simpósio Brasileiro de Engenharia Sanitária e Ambiental, 2000, Porto Seguro, Anais... Porto Seguro, p. 185 - 195.

BRAUN, P. D. K. Desenvolvimento de um modelo de avaliação da capacidade de armazenamento de água na bacia do Rio Itajaí, SC. 197 f. Dissertação (Mestrado em Engenharia. Ambiental) - FURB, Blumenau, 2007.

BRAUN, P. D. K.; VIBRANS, A. C.; PINHEIRO, A. Desenvolvimento de um modelo de avaliação da capacidade de armazenamento de água na bacia do Rio Itajaí, SC. REA - Revista de Estudos Ambientais, Blumenau, v. 10, p. 32 - 44, 2008.

CHIARANDA, R. Usos da terra e avaliação da capacidade potencial de armazenamento de água na bacia do Rio Cuiabá, MT. 352 f. Tese (Doutorado em Engenharia Florestal) - Universidade Federal do Paraná, Curitiba, 2002. 
GUIMARÃES, J. L. B. Relação entre a ocupação do solo e o comportamento hidrológico da Bacia Hidrográfica do Rio Pequeno, São José dos Pinhais, PR. $145 \mathrm{f}$. Tese (Doutorado em Engenharia Florestal) - Universidade Federal do Paraná, Curitiba, 2000.

LIBAULT, C. O. A. Os quatro níveis da pesquisa geográfica: métodos em questão. São Paulo: Instituto de Geografia-USP, 1971. v. 1. 14 p.

LIMA, C. A.; MENDONÇA, F. PLANEJAMENTO URBANO-REGIONAL E CRISE AMBIENTAL: REGIÃO METROPOLITẢA DE CURITIBA. São Paulo Perspec. [online], São Paulo, v. 15, p. 135 143, 2001.

MATTAR NETO, J.; KRÜGER, C. A.; DZIEDZIC, M. Análise de indicadores ambientais no reservatório do Passaúna. Eng. Sanit. Ambient. v. 14, p. 205 - 214, 2009.

SANTOS, A. F. Práticas da agricultura familiar, o uso e ocupação do solo e qualidade da água: a bacia hidrográfica do rio Pequeno, São José dos Pinhais, PR. 223 f. Tese (Doutorado em Meio Ambiente e Desenvolvimento) - Universidade Federal do Paraná, Curitiba, 2006.

SANTOS, A. F.; BERTOTTI, L. G. Avaliação socioambiental da Bacia Hidrográfica do Rio Pequeno, São José dos Pinhais (PR). Ambiência - Revista do Setor de Ciências Agrárias e Ambientais, v. 5, p. 275 - 292, 2009.

SANTOS, I.; KOBIYAMA, M. D. Aplicação do TOPMODEL para zoneamento hidrológico da bacia do rio Pequeno, São José dos Pinhais, PR. In: Simpósio Brasileiro de Desastres Naturais, 2004, Florianópolis. Anais... Florianópolis: GEDN/UFSC, 2004. 1 CD-ROM.

SCHECHI, R. G. Avaliação da capacidade potencial de armazenamento de água da bacia hidrográfica do rio Pequeno, São José dos Pinhais, PR 124 f. Dissertação (Mestrado em Engenharia Florestal) - Universidade Federal do Paraná, Curitiba, 2012.

SOARES, M. R. G. J. Potencial de uso agrícola e fragilidade ambiental como instrumentos voltados ao planejamento da bacia do rio Pequeno, Paraná. 104 f. Dissertação (Mestrado em Ciência do Solo) - Universidade Federal do Paraná, Curitiba, 2008.

SOARES, M. R. G. J.; SOUZA, J. L. M.; JERSZURKI, D. Caracterização do meio físico e formas de uso e ocupação do solo da bacia do rio Pequeno, Paraná. RA`E EA, Curitiba, v. 21, p. 165 - 184, 2011 a.

Potencial de uso agrícola e legislação ambiental voltados ao planejamento na bacia do rio Pequeno, Paraná. RA'E GA, Curitiba, v. 21, p. 186 - 206, 2011 b.

TAVARES, L. P. O. São José dos Pinhais no contexto da recente industrialização metropolitana: reflexos socioespaciais. Revista Paranaense de Desenvolvimento, Curitiba, v. 108, p. 33 - 59, 2005. 